\title{
Article
}

\section{Switched Optimal Control of a Heavy-Duty Hybrid Vehicle}

\author{
Muataz Abotabik ${ }^{t, \ddagger}$ and Richard T. Meyer ${ }^{*, t, \neq(\text { (D) }}$ \\ Department of Mechanical and Aerospace Engineering, Western Michigan University, \\ Kalamazoo, MI 49008, USA; richard.meyer@wmich.com \\ * Correspondence: richard.meyer@wmich.edu \\ † Current address: 1903 Western Michigan Ave., Kalamazoo, MI 49008, USA. \\ $\ddagger$ These authors contributed equally to this work.
}

\section{check for}

updates

Citation: Abotabik, M.; Meyer, R.T. Switched Optimal Control of a Heavy-Duty Hybrid Vehicle. Energies 2021, 14, 6736. https://doi.org/ $10.3390 /$ en14206736

Academic Editor: Ivan Arsie

Received: 25 August 2021

Accepted: 11 October 2021

Published: 16 October 2021

Publisher's Note: MDPI stays neutral with regard to jurisdictional claims in published maps and institutional affiliations.

Copyright: (c) 2020 by the authors. Licensee MDPI, Basel, Switzerland. This article is an open access article distributed under the terms and conditions of the Creative Commons Attribution (CC BY) license (https:// creativecommons.org/licenses/by/ $4.0 /)$.

\begin{abstract}
This work investigates the fuel energy and emission reductions possible with the hybridization of a Class 8 tractor-trailer. The truck tractor has two drive axles: one powered by an internal-combustion-engine-based powertrain (CP) and the other powered by an electric powertrain (EP) consisting of an electric drive system supplied by a battery pack, resulting in a through-the-road hybrid. The EP has two modes of operation depending on the direction of power flow: motoring/battery discharging and generating/battery recharging. Switched optimal control is used to select between the two modes of EP operation, and a recently developed distributed switched optimal control is applied. The control is distributed between the CP, the EP, and the vehicle motion operation components. Control-oriented, component-specific power flow models are set forth to describe the dynamics and algebraic relationships. Four different tractor-trailers are simulated: the original CP and three hybrids with engine sizes of $15 \mathrm{~L}, 11 \mathrm{~L}$, and $7 \mathrm{~L}$. Simulations are performed over a short test cycle and two regulatory driving cycles to compare the fuel use, total energy, and emissions. Results show that the hybrids have reduced fuel use, total energy, and emissions compared to the original $\mathrm{CP}$; the reductions and reference velocity tracking error increases as the engine size is decreased. Particularly, fuel use is reduced by at least $4.1 \%$ under a charge sustaining operation and by $9.8 \%$ when the battery energy can be restored with an off-board charger at the end of the cycle.
\end{abstract}

Keywords: switched optimal control; distributed optimal control; power management; heavy-duty hybrid vehicle

\section{Introduction}

A significant amount of greenhouse gas emissions are produced by the transportation sector. Particularly, internal-combustion-engine-powered heavy-duty vehicles (HDVs) fuelled with diesel are one of the highest energy-intensive freight modes and major greenhouse gas emitters. HDVs produce approximately $16 \%$ of the $\mathrm{CO}_{2}$ worldwide [1], and $20 \%$ of the transportation sector greenhouse emissions [2] in the United States. HDVs are separated in the United States into classes defined by weight limits, where higher class numbers indicate a greater weight limit: Class $2 \mathrm{~b}$ includes vans and heavy-duty pickup trucks, Classes 3-5 include city delivery trucks, Class 7 includes city buses, and Class 8 includes long-haul trucks and coach buses [3] (similar to classes $\mathrm{N}$ and $\mathrm{O}$ in Europe). The global emissions from Class 8 heavy-duty long-haul trucks (Europe Class O4) will more than double in the near future in the absence of mitigating emission policies due to the continuing and strong growth of the on-road transportation sector, especially in developing countries [4]. Policies and actions to mitigate harmful emissions from transportation include vehicle powertrain hybridization and electrification, reductions in carbon intensity of fuel, freight modal shifts, design for demand, and overall vehicle efficiency improvements. Many studies have shown the feasibility of increasing the fuel economy of HDVs up to $30 \%$ by using a variety of drive train technologies as summarized in [4]. The impact of drive train technologies and fuel savings depends on the vehicle operation 
conditions, i.e., whether the vehicle is used for long haul shipments, highly characterized by long steady-state motion periods, or urban traffic, characterized by transient stop-and-go operation [4].

The emission and fuel consumption reduction task is considered difficult due to the diversity and magnitude of the road transportation sector conditions in different countries [4]. Lately, particular attention has been focused on the design, realization, and optimal operation of fully electric or hybrid vehicles [5]. Specifically, an online optimal control strategy for a hybrid power split electric bus based on historical data was proposed in [6]. Their goal is to fully exploit the fuel saving capability of a power split hybrid electric bus under a real-time operating cycle to achieve an effective strategy for solving the optimal calibration problem online. First, they constructed a procedure for synthesizing a real-time driving cycle based on the Markov method and clustered analysis. Second, an optimal controller based on dynamic programming (DP) was developed to investigate fuel economy potential. A rule control method was used as the basis for an online approximation of the DP controller, since DP is not practical for real-time applications. Lastly, a hardware in-the-loop test and offline simulation were conducted. Results showed that the proposed online control gives approximately similar fuel consumption minimization compared to the DP optimal control and achieves real-world improvements.

Lombardi et al. [7] tested six heavy-duty Class 8 truck powertrain configurations: a conventional diesel engine, a diesel engine modified to operate on an organic Rankine cycle (ORC), a diesel-engine-based series hybrid system, an ORC diesel-based series hybrid system, a diesel-engine-based parallel hybrid system, and an ORC diesel-based parallel hybrid system. An optimal control strategy derived from Pontryagin's Minimum Principle was used to minimize the total fuel consumption of the vehicle during the driving cycle and to provide power thresholds needed for a rule-based energy management control strategy. Simulations showed that the parallel hybrids result in the most fuel saving and $\mathrm{CO}_{2}$ reduction.

Energy management control strategy of a hydraulic electric hybrid medium duty vehicle was investigated in [8]. Mathematical models of a pure electric vehicle and a hydraulic electric hybrid vehicle were developed to model the variations of battery charging states and torque through the United States Environmental Protection Agency's New York City Cycle. A rule-based energy management control was proposed. Adjustment of the rule control strategy was performed using a genetic algorithm to refine the vehicle electricity economic performance. Results show that the designed hydraulic hybrid vehicle electricity performance was improved by $36.5 \%$ compared to that of a pure electric vehicle. The energy consumption performance was improved by $43.7 \%$ after applying the genetic algorithm refined strategy.

A nonlinear model predictive control (NMPC) for heavy-duty hybrid electric vehicles using a random power prediction method was proposed in [9]. They combined Markov chains and grey models to produce high-accuracy, ultra-short-term power prediction to account for the lack of navigation information. The predicted power is incorporated into a multi-objective NMPC optimization of bus voltage, a battery state of charge, and fuel consumption. The NMPC was validated in a hardware-in-the-loop simulation platform and compared against other control approaches: rule-based control, fuzzy logic, and dynamic programming. Results showed that the proposed control strategy gives a better all around performance compared to the rule-based and fuzzy approaches. However, the fuel consumption obtained by the online NMPC was approximately $7.7 \%$ more than that achieved by the offline dynamic programming global optimization strategy.

Zhang et al. [10] proposed an adaptive real-time equivalent consumption minimization strategy (ECMS) for a heavy-duty hybrid electric truck. Three main efforts were presented. First, different kinds of driving cycles for a hybrid heavy-duty vehicle were obtained using a neural-network-based driving condition recognition algorithm and a hierarchical clustering algorithm. A particle swarm optimization was then applied to find the optimum ECMS control parameters under a specific driving cycle including a penalty function scale 
factor, an equivalence factor, and a vehicle speed threshold for engine start-up. Finally, the driving condition recognition and optimized ECMS parameters were combined into an adaptive ECMS. The proposed strategy was validated through a numerical simulation with fuel consumption lowered up to $14.8 \%$.

Class 8 trucks with series and parallel hybrid powertrain configurations were simulated in [11] to assess emission and fuel economy controls and component energy losses over highway and urban driving conditions. In this work, a comprehensive set of component models in Autonomie [12] describing emission control, engine fuel consumption, battery energy management, and accessory power demand interactions were integrated and developed with the modeled hybrid trucks to investigate and understand technological barriers to heavy-duty hybrid trucks. Default Autonomie vehicle level hybrid controllers were utilized to manage powertrain components, such as the electric motor, the engine, and the transmission, as well as the fuel consumption minimization management. The study suggests that series hybridization is not practical for the fuel economy improvement of long-haul trucks because of the efficiency penalty that is associated with the dual step of the mechanical-to-electric-to-mechanical energy conversion. However, parallel hybrid technology, in combination with a 50\% auxiliary load reduction, can reduce the fuel consumption by $5-7 \%$ in long-haul trucks. Their study also indicates that hybrid trucks produce fewer emissions, i.e., less hydrocarbons ( $\mathrm{HC}$ ) and carbon monoxides (CO), compared to that produced by the conventional trucks.

Fuel economy and emissions for hybrid and conventional Class 8 heavy-duty diesel trucks operating over multiple highway and urban driving cycles were simulated and compared in [13]. Heavy and light freight loads were considered in this work, and all simulations included an aftertreatment system for particulate matter and NOx emission controls. The hybrid powertrain simulation was configured with a single electric motor between the gearbox and the clutch, and a pre-transmission parallel drive. For comparison, a conventional heavy-duty truck was simulated with a diesel engine and an aftertreatment system. Results showed that the hybridization can improve fuel consumption and emissions significantly in urban driving. The research indicates that there is less potential benefit of hybridization during highway driving due to fewer opportunities to utilize regenerative braking.

Alternative truck powertrains that incorporate a fuel cell have also been investigated in [14-16]. In [14], city buses with diesel, fuel-cell-only, fuel-cell-and-battery hybrid, and fuel-cell-and-battery-plug-in hybrid powertrains were investigated. Single objective optimizations (powertrain cost, life cycle $\mathrm{CO}_{2}$ emissions, and fuel use) and multi-objective optimizations (cost and emissions, emissions and fuel use, and cost and fuel use) were performed over the European Transient Driving Cycle and a bus route using genetic algorithm solution methods. The hybrid powertrains were selected from four different fuel cells, four different electric motors, and eight different batteries. Results of the optimizations showed that the fuel cell powertrains under rule-based control reduced energy use by $58 \%$ and emissions by $67 \%$ with specific recommendations for the powertrain dependent upon vehicle usage and hydrogen and component costs. Di Ilio et al. [15] considered a fuel cell and battery hybrid heavy-duty truck for roll-on/roll-off operation in ports. The proposed powertrain was operated according to a rule-based control and demonstrated the capability of meeting the operation profile while maintaining low hydrogen fuel consumption. Ferrara et al. [16] explored fuel-cell-powered heavy-duty freight transport trucks using operation cycles based on extensive real-world data. Performance was evaluated with respect to the total hydrogen use and the fuel cell power rate of change (since high values result in a greater degradation over time). Six different energy management strategies were implemented including rule-based, model-predictive control, nonlinear programming, equivalent consumption minimization, and Pontryagin's Minimum Principle to (i) minimize fuel use and (ii) maximize lifetime and minimize fuel use. Each control strategy resulted in different acceptable outcomes, with the model predictive control showing both low fuel use and a high lifetime. Additionally, Samsum et al. [17] investigated the use 
of a fuel-cell-based auxiliary power unit to supply truck electrical loads during layovers, finding that practical system efficiency improved by $28 \%$.

The novelty and contributions of this work are (1) the development of new, controloriented, operating-mode-specific power flow models for a heavy-duty hybrid vehicle powertrain, (2) the definition of a complete set of Class 8 heavy-duty hybrid truck tractor parameters compatible with the power flow models, (3) the application of a recently developed distributed switched optimal control solution method to the power management of both a conventional and a hybrid truck tractor, and (4) the comparison of a conventional internal combustion engine (ICE) truck tractor and three different heavy-duty truck tractor configurations, delineated by their ICE engine displacements, with respect to fuel, total energy, and $\mathrm{CO}_{2}$ emissions over government regulatory driving cycles while moving a fully loaded trailer. These actions support the testing of the hypothesis that a through-the-road hybrid with a reduced engine displacement will result in reduced fuel use, total energy, and $\mathrm{CO}_{2}$ emissions compared to the original vehicle.

In the following, Section 2 develops the needed control models for the combustion powertrain, electrical powertrain, and vehicle motion dynamics. Next, Section 3 reviews the distributed switched optimal control with respect to hybrid truck tractor power management. Section 4 gives control simulation results for an ICE-only truck tractor and three different hybrid truck tractor configurations over a short, severe-duty trapezoidal driving cycle and several government regulatory driving cycles. Comparisons are made between the performance of the ICE-only truck and the hybrid trucks with respect to fuel use, total energy use, and $\mathrm{CO}_{2}$ emissions using regulatory profile results. Conclusions and future work directions are set forth in Section 5.

\section{Powertrain Models and Controls}

The heavy-duty hybrid vehicle studied is a Class $86 \times 4$ (three axles with two drive axles) truck tractor with a high roof sleeper cab and a long dry van trailer with a maximum payload of $19 \times 10^{3} \mathrm{~kg}$. The original combustion engine powertrain $(\mathrm{CP})$ is taken from the United States Environmental Protection Agency's Greenhouse Gas Emissions Model (GEM), version 3.8 [18], with a $339 \mathrm{~kW} 15 \mathrm{~L}$ diesel engine and a transmission with gear ratios from 12.80 to 0.73 . To create a hybrid vehicle, the combustion engine and transmission are connected to only one drive axle, while the other drive axle is connected to an electrical powertrain (EP). Figure 1 displays the potential power flows of the combined combustionbased and electrical-based propulsion systems. The vehicle is a through-the-road hybrid that can transfer mechanical power from the combustion engine to the battery through the road, as illustrated with the horizontal mechanical power (blue) lines from the left set of wheels (driven by the combustion engine) to the right set (connected to the electric powertrain); there is no driving-independent power transfer connection between the $\mathrm{CP}$ and EP. The electrical powertrain consists of a $225 \mathrm{~kW}$ induction motor, an AC-DC inverter electric drive system (EDS), and a $59.6 \mathrm{kWh}$ lithium-Ion battery, common sizes already commercially available for light vehicles [19]; the EP alone cannot provide for all driving duties. The hybrid truck tractor is modeled with the original $15 \mathrm{~L}$ engine as well as downsized diesel engines of $11 \mathrm{~L}$ ( $261 \mathrm{~kW}$ maximum power) and $7 \mathrm{~L}$ (149 kW maximum power).

The vehicle power management chooses the power flows of the CP and EP to both move the vehicle and consume kinetic energy to recharge the battery. The management control problem is a switched control problem since both the electric drive system and battery have unique dynamics based on the direction of the power flow. Switched control problems have been widely studied for a range of applications, cf. [20,21]. The EP has two modes of operation: EDS motoring/battery discharging and EDS generating/battery charging. The combined $\mathrm{CP}$ and EP power management is performed using a distributed switched system control introduced in [19]. Accessory power loads are not considered, since they are often taken as constant values [18], and our focus is on the dynamic power delivered to drive the vehicle. The component models and control cost functions are 
presented next. The different components are connected together using complicating variables, where the vector of complicating variables is $\psi=\left[P_{c p}^{p}, \omega_{c p}^{p}, P_{d, m^{\prime}}^{p}, \omega_{e}^{p}\right]^{\top}: P_{c p}^{p}$ is the power at the $\mathrm{CP}$ transmission output, $\omega_{c p}^{p}$ is the $\mathrm{CP}$ transmission output angular velocity, $P_{d, m}^{p}$ is the EP motor electrical power, and $\omega_{e}^{p}$ is the EP motor angular velocity.

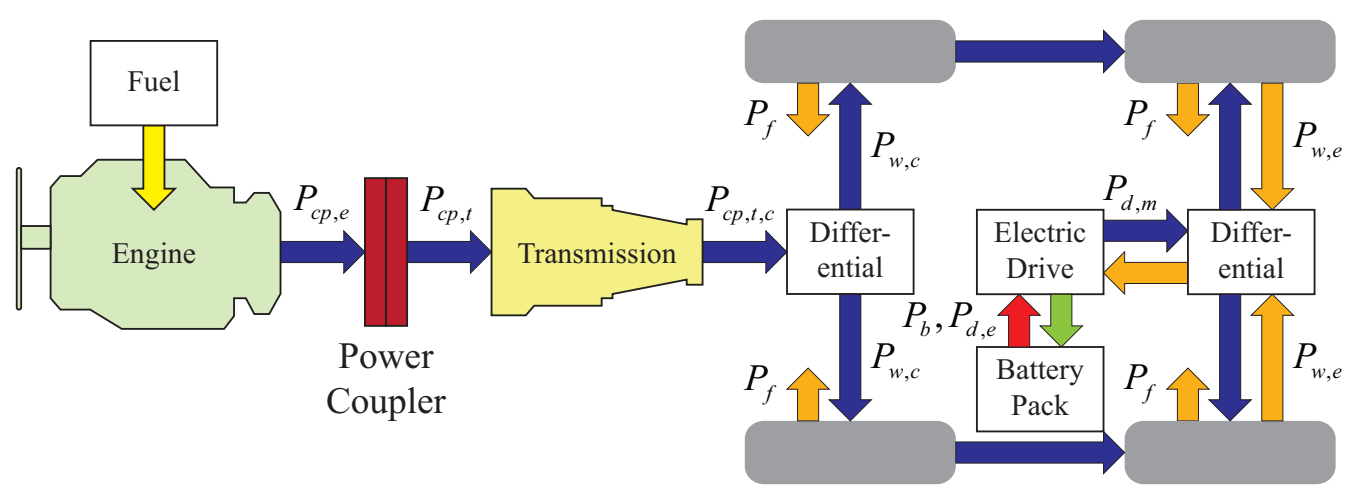

Figure 1. Class 8 truck tractor through-the-road hybrid powertrain potential power flows: $(\square)$ electrical power produced; ( $\square$ ) electrical power consumed; $(\square)$ mechanical power produced; $(\square)$ mechanical power consumed. $P_{c p, e}$ : engine power, $P_{c p, t}$ : engine power on transmission side; $P_{c p, t, c}$ : transmission output power; $P_{b}$ : battery power; $P_{d, e}$ : electrical drive system electrical power; $P_{d, m}$ : electric drive system mechanical power; $P_{w, c}$ : combustion-based wheel power; $P_{w, e}:$ electrical-based wheel power; $P_{f}$ : wheel frictional braking power.

\subsection{Combustion Engine Powertrain}

The $\mathrm{CP}$ includes the diesel engine, transmission, and power coupler that joins them. The $15 \mathrm{~L}, 11 \mathrm{~L}$, and $7 \mathrm{~L}$ diesel engine output power and fuel consumption models are derived from the data provided in GEM [18]. The power and fuel consumption are algebraic models since the dynamics of the engine are much faster than that of vehicle motion:

$$
\begin{aligned}
P_{c p, e}^{\max } & =\beta_{e, 0}+\beta_{e, 1} \omega_{c p, e}+\beta_{e, 2} \omega_{c p, e}^{2}+\beta_{e, 3} \omega_{c p, e}^{3} \\
P_{c p, e} & =P_{c p, e}^{\max } u_{c p} \\
\frac{d \omega_{c p, e}}{d t} & =\frac{1}{\tau_{\omega_{c p, e}}}\left[-\omega_{c p, e}+\left(\omega_{c p, e}^{\max }-\omega_{c p, e}^{\min }\right) u_{c p, \omega}\right] \\
W_{c p, f} & =\beta_{f, 0}+\beta_{f, 1} \omega_{c p, e}+\beta_{f, 2} P_{c p, e}
\end{aligned}
$$

where $P_{c p, e}^{\max }$ is the maximum engine power regulated by $u_{c p} \in[0,1]$ to obtain the output power $P_{c p, e}, W_{c p, f}$ is the fuel mass flow rate, $\omega_{c p, e}$ is the engine angular velocity regulated by $u_{c p, \omega} \in[0,1], \omega_{c p, e}^{\min }$ and $\omega_{c p, e}^{\max }$ are the lower and upper limits of $\omega_{c p, e}, \tau_{\omega_{c p, e}}$ is the time constant of engine speed response, and $\beta_{e, i}$ and $\beta_{f, i}$ are fit coefficients. The forms of Equations (1) and (4) were determined empirically from the fitting of experimental engine data given in [18]. Equation (2) is a typical regularization to define control inputs over the unit interval to ease eventual numerical optimization. Equation (3) prevents sudden changes in engine speed when it is decoupled from the transmission. The modeling parameters for Equations (1)-(4) for each engine are listed in Tables A1 and A2 in Appendix A; Figure 2 shows the resulting maximum power curve and fuel flow contours for the $15 \mathrm{~L}$ engine. 


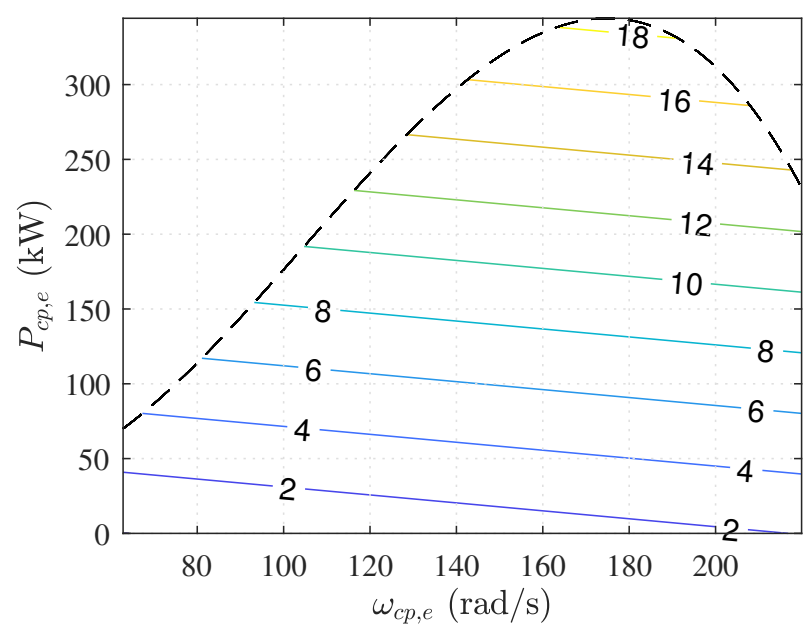

Figure 2. $15 \mathrm{~L}$ diesel engine fuel consumption $(\mathrm{g} / \mathrm{s})$ contour map obtained from experimental data in [18]: (- ) maximum power.

The power coupler between the engine and transmission is an idealized device that transitions between the open and closed states in a nonzero finite time. In the open state, $P_{c p, e}$ is not transferred to the drive wheels, and the engine speed and transmission speed are independent. The open-to-closed transition is initiated when the time derivative of the vehicle longitudinal velocity reference (described in Section 4) is increasing more than $0.02 \mathrm{~m} / \mathrm{s}^{2}$ over time, resulting in power transfer across the coupler:

$$
P_{c p, e}\left(\omega_{c p, t}+\epsilon\right)=P_{c p, t} \omega_{c p, e}
$$

where $P_{c p, t}$ is the power at the transmission input, $\omega_{c p, t}$ is the angular velocity at the transmission input, and $\epsilon<<1$ provides for starting the vehicle from zero velocity. The power coupler is considered closed when the transmission speed satisfies $\omega_{c p, t} \geq \omega_{c p, e}$. Upon closure, $P_{c p, e}=P_{c p, t}$ and $\omega_{c p, e}=\omega_{c p, t}$ (the latter constraint removes the choice of $\left.u_{c p, \omega}\right)$. Conversely, the power coupler transitions from closed to open when the velocity reference is decreasing by at least $-0.02 \mathrm{~m} / \mathrm{s}^{2}$ or more or the vehicle is stopped. The logic was sufficient to operate the original truck in simulation and is applied to the hybrid trucks as well. The forthcoming control regulates the engine power and speed such that $P_{c p, t}$ is sufficient to begin motion given rolling resistance, slopes, etc.

The transmission is a CVT with a gear ratio, $\gamma_{c p} \in[0.73,12.8]$, the same span as the stepped transmission in [18]. The output speed of the transmission is $\omega_{c p, t, c}=\omega_{c p, t} / \gamma_{c p}$, and the output power is idealized as $P_{c p, t, c}=P_{c p, t}$. The transmission is connected to the remainder of the vehicle with the complicating variables, $P_{c p}^{p}$ and $\omega_{c p}^{p}$, which represent the power provided by the $\mathrm{CP}$ and the angular velocity at the transmission output, respectively:

$$
A_{c p} z_{c p}-B_{c p} \psi=\left[\begin{array}{c}
\eta_{f d} P_{c p, t, c}-P_{c p}^{p} \\
\omega_{c p, t, c}-\omega_{c p}^{p}
\end{array}\right]=0
$$

where $z_{c p}=\left[P_{c p, e}, P_{c p, t}, P_{c p, t, c,}, W_{c p, f}, \omega_{c p, e}, \omega_{c p, t}, \omega_{c p, t, c}, u_{c p}, u_{c p, \omega}\right]^{\top}, \psi$ is the vector of all complicating variables listed previously, $\eta_{f d}$ is the final drive gear efficiency between the transmission output and axle, and $A_{c p}$ and $B_{c p}$ are appropriate constant matrices needed for the control formulation in Section 3.

The CP power management optimal control problem is

$$
\min _{u_{c p}, u_{c p, \omega}, \gamma_{c p}} \int_{t_{p, 0}}^{t_{p, f}} q_{c p, W_{f}}\left(W_{c p, f}(t)\right)^{2} d t
$$

subject to Equations (1)-(6) and convex and compact variable bounds, where $\left[t_{p, 0}, t_{p, f}\right]$ is the power management prediction horizon, $t_{p, 0}$ is the current time, and $q_{c p, W_{f}}$ weighs the 
fuel use penalty. We note that penalizing fuel use is equivalent to penalizing $\mathrm{CO}_{2}$ emissions as in [18].

\subsection{Electrical Powertrain}

The electrical powertrain consists of the battery and EDS operating together. The EDS is a $225 \mathrm{~kW}$ maximum power induction motor coupled with a bidirectional AC-DC inverter. The EDS can either operate in motoring mode to propel the vehicle or battery regenerative mode to consume excess vehicle kinetic energy. The mode is controlled by a switched variable, $\alpha_{d}$, that is 0 when motoring and 1 when generating. The EDS electrical dynamics are much faster than the vehicle motion dynamics and are modeled algebraically with motoring electrical power $P_{d, e^{\prime}}^{0}, P_{d, m}^{0} \geq 0$ :

$$
\begin{aligned}
& P_{d, m}^{0}=P_{d, m}^{\max }\left(\omega_{d}\right) u_{d}^{0} \\
& P_{d, e}^{0}=\frac{\eta_{d, m}\left(P_{d, m^{\prime}}^{0} \omega_{d}\right)}{\eta_{d, i n v}} P_{d, m}^{0}
\end{aligned}
$$

Generating is modeled similarly with $P_{d, e^{\prime}}^{1}, P_{d, m}^{1}<0$ :

$$
\begin{aligned}
P_{d, m}^{1} & =-P_{d, m}^{\max }\left(\omega_{d}\right) u_{d}^{1} \\
P_{d, e}^{1} & =\eta_{d, m}\left(P_{d, m}^{1}, \omega_{d}\right) \eta_{d, i n v} P_{d, m}^{1},
\end{aligned}
$$

$\eta_{d, m}$ is the propelling/generating motor power transfer efficiency, shown in Figure 3, developed from induction motor modeling, field-oriented control, and field-weakening control methods in [22,23] using data in [24]:

$$
\begin{aligned}
\eta_{d, m}\left(P_{d, m}^{\alpha_{d}}, \omega_{d}\right) & =c_{d, 1} \frac{P_{d, m}^{\alpha_{d}}}{\beta\left(\omega_{d}+\epsilon_{d}\right)^{2}}+c_{d, 2} \frac{\beta}{P_{d, m}^{\alpha_{d}}+\epsilon_{d}}+1 \\
\beta & = \begin{cases}1, & 0 \leq \omega_{d} \leq \omega_{d, r} \\
\left(\frac{\omega_{d, r}}{\omega_{d}}\right)^{2}, & \omega_{d, r}<\omega_{d} \leq 16000 \pi / 30 \mathrm{rad} / \mathrm{s}\end{cases}
\end{aligned}
$$

where $\omega_{d}$ is the motor shaft angular speed, $\eta_{d, i n v}=0.95$ is the inverter efficiency, $\beta$ captures the field weakening above the rated speed $\omega_{d, r}=5000 \pi / 30 \mathrm{rad} / \mathrm{s}, c_{d, 1}=5.08 \times 10^{-2}$ and $c_{d, 2}=26.9$ are motor-parameter-derived constants, $\epsilon_{d} \ll 1$ is a regularization term to prevent division by zero at zero speed and/or zero mechanical power, and $u_{d}^{0}, u_{d}^{1} \in[0,1]$ regulates the maximum mechanical power, given in Equation (A1) in Appendix A, in motoring and generating, respectively. The rated speed denotes the separation point in motor control: below the rated speed, the motor operates under field-oriented control with the maximum power set by the stator current limit and above the rated speed, the motor operates under field-weakening control where the maximum power begins to decrease linearly after $8000 \pi / 30 \mathrm{rad} / \mathrm{s}$ due to a maximum voltage limit.

Since there is not a single mechanical power value to use to connect with other components, a mode-weighted mechanical power value, $P_{d, m, c}$, is formed:

$$
P_{d, m, c}=\left(1-\alpha_{d}\right) \eta_{f d} P_{d, m}^{0}+\alpha_{d} \frac{P_{d, m}^{1}}{\eta_{f d}}
$$



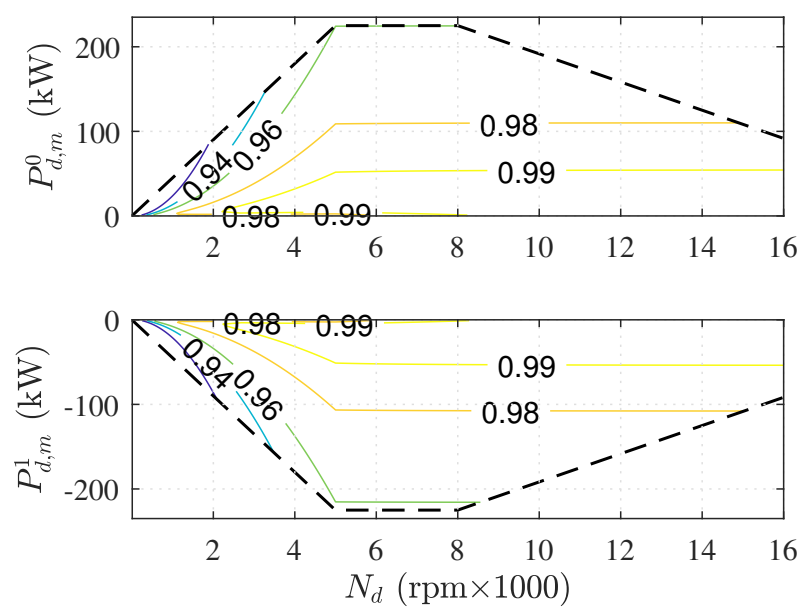

Figure 3. Electric drive system motor propelling electrical to mechanical power conversion efficiency contours (upper) and generating mechanical to electrical power conversion efficiency contours (lower) without the inclusion of inverter efficiency: (- $)$ mechanical power limit.

The lithium-ion battery that is connected to the EDS inverter to supply and absorb energy stores $59.6 \mathrm{kWh}$. The battery has two modes of operation, discharging and charging, which correspond to the EDS motoring and propelling modes. The mode switched dynamics are

$$
\begin{gathered}
\frac{d \bar{W}_{b}}{d t}=\left(1-\alpha_{d}\right)\left(-\frac{P_{b}^{0}}{\eta_{b}^{0} W_{b}^{\max }}\right)+\alpha_{d}\left(-\eta_{b}^{1} \frac{P_{b}^{1}}{W_{b}^{\max }}\right) \\
k^{\alpha_{d}} \ln \left(\bar{W}_{b}+c_{b, 1}^{\alpha_{d}}\right)+c_{b, 2}^{\alpha_{d}} P_{b}^{\alpha_{d}}+c_{b, 3}^{\alpha_{d}}+c_{b, 4}^{\alpha_{d}}\left(P_{b}^{\alpha_{d}}\right)^{2}= \begin{cases}1 / \eta_{b}^{0}, & \alpha_{d}=0 \\
\eta_{b}^{1}, & \alpha_{d}=1\end{cases}
\end{gathered}
$$

where $\bar{W}_{b}$ is the state of charge (SOC), $W_{b}^{\max }$ is the battery's maximum energy, $\alpha_{d}$ is the battery mode switch variable with $\alpha_{d}=0$ for discharge and $\alpha_{d}=1$ for charge, $P_{b}^{\alpha_{d}}$ is the mode-specific battery power with $P_{b}^{0} \in[0,420] \mathrm{kW}$ for discharge and $P_{b}^{1} \in[-420,0) \mathrm{kW}$ for charge, $\eta_{b}^{\alpha_{d}}$ is the discharge/charge efficiency, and $k^{0} / k^{1}$ and $c_{b, i}^{0} / c_{b, i}^{1}, i=1, \ldots, 4$, are discharge/charge fit coefficients. Figure 4 displays the discharge/charge efficiencies from values in Table A3 in Appendix A, which was sourced from data in [24].
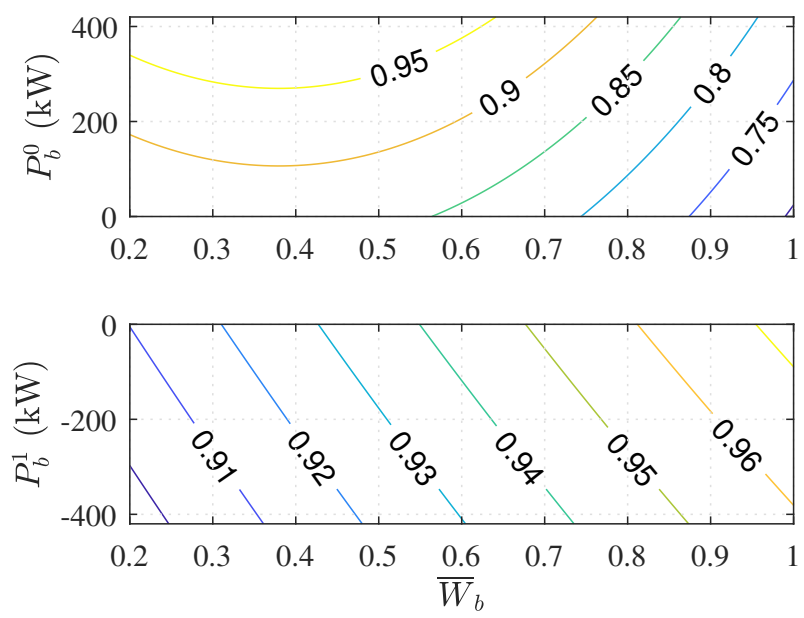

Figure 4. Battery discharge (upper) and charge (lower) efficiency contours for the state of charge and power regions. 
The battery power is rate-limited to prevent battery damage from high frequency operation:

$$
\left|\frac{d P_{b}^{\alpha_{d}}}{d t}\right| \leq \Delta_{P_{b}}
$$

where $\Delta_{P_{b}}=15 \mathrm{~kW} / \mathrm{s}$ is the power rate limit magnitude determined from previous electric vehicle work [24].

The battery and EDS are joined together by mode-specific connections

$$
\begin{aligned}
& P_{b}^{0}=P_{d, e}^{0} \\
& P_{b}^{1}=P_{d, e}^{1}
\end{aligned}
$$

and the overall EP is connected to the complicating variables, $P_{d, m}^{p}$ and $\omega_{e}^{p}$, with

$$
A_{d} z_{d}-B_{d} \psi=\left[\begin{array}{c}
P_{d, m, c}-P_{d, m}^{p} \\
\omega_{d}-\omega_{e}^{p}
\end{array}\right]=0
$$

where $z_{d}=\left[P_{d, e^{\prime}}^{0}, P_{d, e^{\prime}}^{1} P_{d, m}^{0}, P_{d, m}^{1}, P_{d, m, c}, \omega_{d}, u_{d}^{0}, u_{d}^{1}, \alpha_{d}, \bar{W}_{b}, P_{b, c}, P_{b}^{0}, P_{b}^{1}\right]^{\top}$ and $A_{d}$ and $B_{d}$ are appropriate constant matrices needed for the control formulation in Section 3.

The EP can operate in either motoring/discharging or generating/charging modes, which results in a switched optimal control problem:

$$
\min _{\alpha_{d}, u_{d}^{0}, u_{d}^{1}} \int_{t_{p, 0}}^{t_{p, f}} q_{b, \bar{W}_{b}}\left(\bar{W}_{b, r e f}(t)-\bar{W}_{b}(t)\right)^{2} d t
$$

subject to Equations (8)-(19) and convex and compact variable bounds where $q_{b, \bar{W}_{b}}$ is the penalty weight on the deviation of the SOC from the desired value.

\subsection{Vehicle Operation Motion}

The total vehicle includes the $6 \times 4$ truck tractor and trailer. The vehicle dynamics are modeled using energy conservation applied to point-mass, linear motion:

$$
\begin{aligned}
\frac{d \mathrm{Y}}{d t} & =\frac{2}{m_{v}}\left[P_{d}(v)+P_{r r}\left(v, \theta_{r}\right)+P_{g}\left(\theta_{r}\right)+\left(P_{w, c}+P_{w, e}-P_{f}\right)\right] \\
P_{d}(v) & =v \cdot\left(-0.5 \rho_{a i r} A C_{d} v^{2} \operatorname{sgn}(v)\right) \\
P_{r r}\left(v, \theta_{r}\right) & =v \cdot\left(-C_{r r} m_{v} g \cos \left(\theta_{r}\right) \operatorname{sgn}(v)\right) \\
P_{g}\left(\theta_{r}\right) & =v \cdot\left(-m_{v} g \sin \left(\theta_{r}\right)\right)
\end{aligned}
$$

where $\mathrm{Y}=v^{2}$ ( $v$ is velocity), $P_{d}$ is the drag force power, $P_{r r}$ is the rolling resistance, $P_{g}$ is the power due to the body gravity force, $P_{w, c}$ is the wheel power from the $\mathrm{CP}, P_{w, e}$ is the wheel power from the EP, $P_{f}$ is the total frictional braking power, $m_{v}$ is the vehicle mass including load, $A C_{d}$ is the product of the vehicle frontal area and drag coefficient, $C_{r r}$ is the tire rolling resistance, $\rho_{\text {air }}$ is the ambient air density, and $\theta_{r}$ is the road grade angle. The total truck tractor and trailer braking is proportional to the velocity:

$$
P_{f}=P_{f}^{\max }\left(0.99 \frac{v}{v^{\max }}+0.01\right) u_{f}
$$

where $P_{f}^{\max }$ is the maximum braking power, $v^{\max }$ is the maximum velocity, and $u_{f} \in[0,1]$ controls the applied braking power; note that a braking force is applicable at zero velocity. 
The vehicle is joined to the $\mathrm{CP}$ and EP with complicating variables, $P_{c p}^{p}, P_{d, m}^{p}, \omega_{c p}^{p}$, and $\omega_{e}^{p}$ :

$$
A_{v} z_{v}-B_{v} \psi=\left[\begin{array}{c}
P_{w, c}-P_{c p}^{p} \\
P_{w, e}-P_{d, m}^{p} \\
\omega_{v} \gamma_{v, c}-\omega_{c p}^{p} \\
\omega_{v} \gamma_{v, e}-\omega_{e}^{p}
\end{array}\right]=0
$$

where $\omega_{v}=v / r_{w h l}$ is the angular velocity of the axle shafts, $r_{w h l}$ is the wheel radius, $\gamma_{v, c}$ is the final drive ratio between the $\mathrm{CP}$ and axle, $\gamma_{v, e}$ is the final drive ratio between the EP and axle, $z_{v}=\left[Y, P_{f}, P_{w, c}, P_{w, e}, u_{f}, \omega_{v}\right]^{\top}$, and $A_{v}$ and $B_{v}$ are appropriate matrices needed for the control formulation in Section 3. All vehicle parameters are listed in Table A4 in Appendix A.

The vehicle motion optimal control is to perform velocity reference tracking and frictional braking management. The control problem is

$$
\min _{P_{w, c}, P_{w, e}, u_{f}} \int_{t_{p, 0}}^{t_{p, f}} q_{v, Y}\left(Y_{r e f}(t)-\mathrm{Y}(t)\right)^{2}+q_{v, b r k}\left(P_{f}(t)\right)^{2} d t
$$

subject to Equations (21)-(23) and convex and compact variable bounds where $q_{v, Y}$ weighs the deviation of the tracking from the reference $\mathrm{Y}_{r e f}$, and $q_{v, b r k}$ weighs the use of friction braking to make regenerative braking preferred.

\section{Distributed Control}

The total vehicle power management must coordinate the combustion powertrain and electrical powertrain composed of the battery and EDS to meet the vehicle driving demands. The continuous-time component level control problems are approximated in discrete-time with a time step of $h$ using forward-Euler and trapezoidal numerical integration. The discrete-time control problems are solved in a receding horizon and distributed manner using the method presented in [19] that is based on the popular alternating direction method of multipliers. To apply the method in [19], the discrete-time component level cost functions are expanded to include the complicating variable connection constraints and a penalty on the connection constraint violation, resulting in the optimal control problem:

$$
\min _{Z_{i, k}} \sum_{n=1}^{N} \bar{J}_{i}\left(z_{i, k+n}\right)+\left\langle\lambda_{i, k+n}, A_{i} z_{i, k+n}-B_{i} \psi_{k+n}\right\rangle+\frac{\rho}{2}\left\|A_{i} z_{i, k+n}-B_{i} \psi_{k+n}\right\|_{2}^{2}
$$

subject to

$$
Z_{i, k} \in \mathcal{Z}_{i}\left(x_{i, k}\right)
$$

where $k$ is the time index; $N$ is the prediction horizon; $i$ indicates the component; $\bar{J}_{i}$ is the trapezoidal numerical integration representation of the cost function; $Z_{i, k}=\left[z_{i, k+1}^{\top}, \ldots, z_{i, k+N}^{\top}\right]^{\top}$ with $z_{i, k+n}=\left[x_{i, k+n}^{\top}, y_{i, k+n-1}^{\top}, u_{i, k+n-1}^{\top}, \alpha_{i, k+n-1}^{\top}\right]^{\top}$, where $x_{i}$ is the state vector, $y_{i}$ is the algebraic variables vector, $u_{i}$ is the continuous control inputs vector, and $\alpha_{i}$ are the mode switches; $\Psi_{k}=\left[\psi_{k+1}^{\top}, \ldots, \psi_{k+N}^{\top}\right]^{\top}$, with $\psi_{k+n}$ denoting the complicating variables at $k+n ; \mathcal{Z}_{i}$ is the feasible region that is dependent on $x_{i, k}=x_{i}\left(t_{p, 0}\right)$, the initial state, and includes the dynamic and algebraic constraints and convex and compact variable bounds. With respect to the distributed control formulation, $\lambda_{i}$ is the dual variable, and $\rho$ is a penalty parameter. The distributed solution method in [19] iterates until the convergence conditions are met:

$$
r=\left[\begin{array}{c}
{\left[A_{1}\right] Z_{1, k}^{l+1}-\left[B_{1}\right] \Psi_{k}^{l+1}} \\
\vdots \\
{\left[A_{n_{c}} Z_{n_{c}, k}^{l+1}-\left[B_{n_{c}}\right] \Psi_{k}^{l+1}\right.}
\end{array}\right], \quad\|r\|_{2} \leq \epsilon_{r}
$$




$$
s=\left[\begin{array}{c}
\rho^{l}\left[A_{1}\right]^{\top}\left[B_{1}\right]\left(\Psi_{k}^{l+1}-\Psi_{k}^{l}\right) \\
\vdots \\
\rho^{l}\left[A_{n_{c}}\right]^{\top}\left[B_{n_{c}}\right]\left(\Psi_{k}^{l+1}-\Psi_{k}^{l}\right)
\end{array}\right], \quad\|s\|_{2} \leq \epsilon_{s}
$$

where $\left[A_{i}\right]=I_{N} \otimes A_{i}$ is the Kronecker product that results in an $n_{A_{i}, r} N \times n_{A_{i}, c} N$ matrix with a diagonal arrangement of $A_{i} \in \mathbb{R}^{n_{A_{i}, r} \times n_{A_{i}, c}}$ blocks repeated $N$ times, $\left[B_{i}\right]=I_{N} \otimes B_{i}$ is a similar Kronecker product to $\left[A_{i}\right], l$ is a solution algorithm index, $n_{c}$ is the number of connected components, and $\epsilon_{r}$ and $\epsilon_{S}$ are tolerances.

The EDS and battery are both switched components and have control problems that include discrete-valued mode switches. To avoid the computational complexity associated with discrete-valued mode switches [20], the embedding method is applied, where $\alpha_{d} \in\{0,1\}$ are relaxed to $[0,1]$, i.e., replaced with $\tilde{\alpha}_{d} \in[0,1]$. The resulting problems with all continuous-valued variables are embedded optimal control problems (EOCPs). If an EOCP solution results in any $\tilde{\alpha}_{d} \in(0,1)$, then the embedded solution must be projected back to $\{0,1\}$, and the projected optimal control problem (POCP) must be solved to obtain the control inputs to be applied. Here the projection utilizes the connection power values. For the EDS when $\tilde{\alpha}_{d} \in(0,1)$, if $P_{d, m, c} \geq 0$, then the mode is propelling and generating otherwise. If projection is necessary, the distributed control is solved a second time with the projected mode values enforced. The optimal control problems formulated for the distributed solution meet the conditions for the existence of an EOCP solution and convergence of the distributed solution as outlined in $[19,20]$.

\section{Control Simulation}

The Class 8 heavy-duty tractor truck with a trailer is simulated over three different driving cycles while transporting the maximum load of 19,000 kg: a trapezoidal driving cycle, the California Air Resources Board Highway's Heavy-Duty Diesel Transient driving cycle with varying road angles, and the new European driving cycle. The latter two driving cycles are used to evaluate the hypothesis. The maximum load is chosen since it puts the most stress on the powertrain and control as well. The simulation time step is $h=0.5 \mathrm{~s}$, and the prediction horizon is $N=2$. The distributed control is applied with $\epsilon_{r}, \epsilon_{s}=0.2$. We do not assume that the control has perfect knowledge of either the driving cycle velocity or road angle over the prediction horizon. The driving cycle velocity is linearly extrapolated from velocity at the current time and the requested velocity. These velocities are squared to create the reference kinetic energy:

$$
\mathrm{Y}_{r e f, k+n}=\left[v_{k}+n\left(v_{r e f, k+1}-v_{k}\right)\right]^{2}, \quad n=0, \ldots, N
$$

where $v_{k}$ is the current velocity at $t_{p, 0}$, and $v_{r e f, k+1}$ is the desired velocity that is delayed to one step ahead (the velocity is delayed since the velocity cannot instantly change). The road angle is not linearly extrapolated over the prediction horizon like the velocity; rather, the angle value at $t_{p, 0}$, the driving cycle time associated with the start time of the current control calculation, is held constant over the prediction horizon.

The control of the different truck tractor powertrains utilizes the same component cost function penalty weights that were chosen after experimentation: $q_{c p, W_{f}}=10$, $q_{v, \mathrm{Y}}=6.5 \times 10^{4}, q_{v, \text { brk }}=4 \times 10^{6} / P_{f}^{\max }$, and

$$
q_{b, \bar{W}_{b}}= \begin{cases}1 \times 10^{8} \frac{\left(\bar{W}_{b}\left(t_{p, 0}\right)-\bar{W}_{b}^{\text {min }}\right)^{2}}{\left(\bar{W}_{b, r e f}-\bar{W}_{b}^{\text {min }}\right)^{2}}, & \bar{W}_{b}\left(t_{p, 0}\right)<\bar{W}_{b, r e f} \\ 0, & \text { otherwise }\end{cases}
$$

where $\bar{W}_{b}^{\min }=0.2$ is the minimum SOC, and $\bar{W}_{b, r e f}=0.8 ; q_{b, \bar{W}_{b}}$ penalizes the decrease of the SOC more as it falls further below the reference value but does not penalize lowering 
the SOC, i.e., the use of the battery, when the SOC is above the reference. The starting SOC in all simulations is 0.8 . Further, the simulations are performed in units of $\mathrm{m}, \mathrm{kg}, \mathrm{W}$, radians, and seconds. The $15 \mathrm{~L}$ original ICE powertrain is referred to as $15 \mathrm{~L}-\mathrm{ICE}$, and the hybrid vehicles are referred to by engine displacement as 15L-H, 11L-H, and 7L-H.

\subsection{Trapezoidal Drive Cycle}

The trapezoidal driving cycle consists of a $35 \mathrm{~s}$ constant acceleration to $11.176 \mathrm{~m} / \mathrm{s}$ $(25 \mathrm{mph})$, a $5 \mathrm{~s}$ constant velocity portion, and then a constant deceleration to zero over the final $35 \mathrm{~s}$. The short time profile is meant to demonstrate the operating behavior of the powertrain compared to much longer regulatory profiles with many acceleration/deceleration events. Figure 5 shows the performance of the 15L-H over the velocity profile, and Table 1 shows the mean absolute percentage error (MAPE), the 2-norm normalized error N2NE (the 2-norm normalized error is equal to $100 \% \times\left\|x-x_{\text {ref }}\right\|_{2} /\left\|x_{\text {ref }}\right\|_{2}$ ), the final battery SOC, and the total fuel use. All of the powertrains result in acceptable velocity tracking with the greatest MAPE of $0.78 \%$ and an N2NE of $0.34 \%$. The hybrids have effectively the same SOC at the end of the profile and a lower fuel use than the 15L-ICE, with 15L-H $87.3 \%$ less, $11 \mathrm{~L}-\mathrm{H}$ 87.7\% less, and 7L-H $83.1 \%$ less. Even over the short trapezoidal profile, the ability to use the battery and regeneratively brake provides a benefit compared to the 15L-ICE.
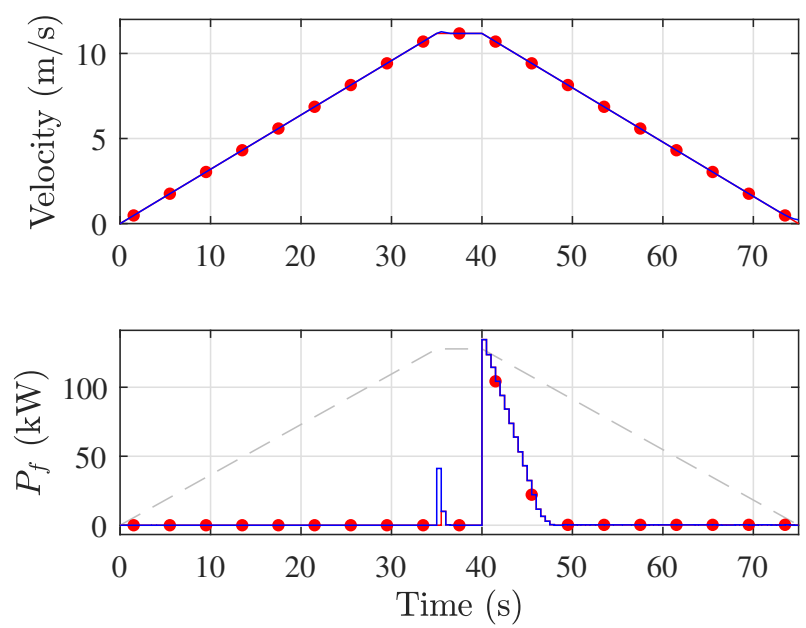

Figure 5. 15L-H truck tractor velocity (upper) and frictional braking power (lower) over the trapezoidal driving cycle: $(-)$ POCP value, $(\bullet)$ EOCP value, $(--)$ superimposed driving cycle.

To better understand the hybrid operation, the 15L-H CP and EP performance is examined. Figure 6 shows the engine power, cumulative fuel use, and engine speed of the $15 \mathrm{~L}-\mathrm{H}$. The power rises with velocity, stays relatively unchanged over the constant velocity portion while providing motoring power, and then the engine is idle during deceleration. The 15L-ICE shows a much larger, nearly linearly increase in power with velocity during the acceleration portion since there is no EP to provide support. The maximum 15L-H engine power is $36.0 \mathrm{~kW}$, while the $15 \mathrm{~L}-\mathrm{ICE}$ is $225.3 \mathrm{~kW}$, an increase of $525.8 \%$. Further, the maximum 11L-H ICE power is similar to the $15 \mathrm{~L}-\mathrm{H}$ value, but the $7 \mathrm{~L}-\mathrm{H}$ value is lower at $31.9 \mathrm{~kW}$. 

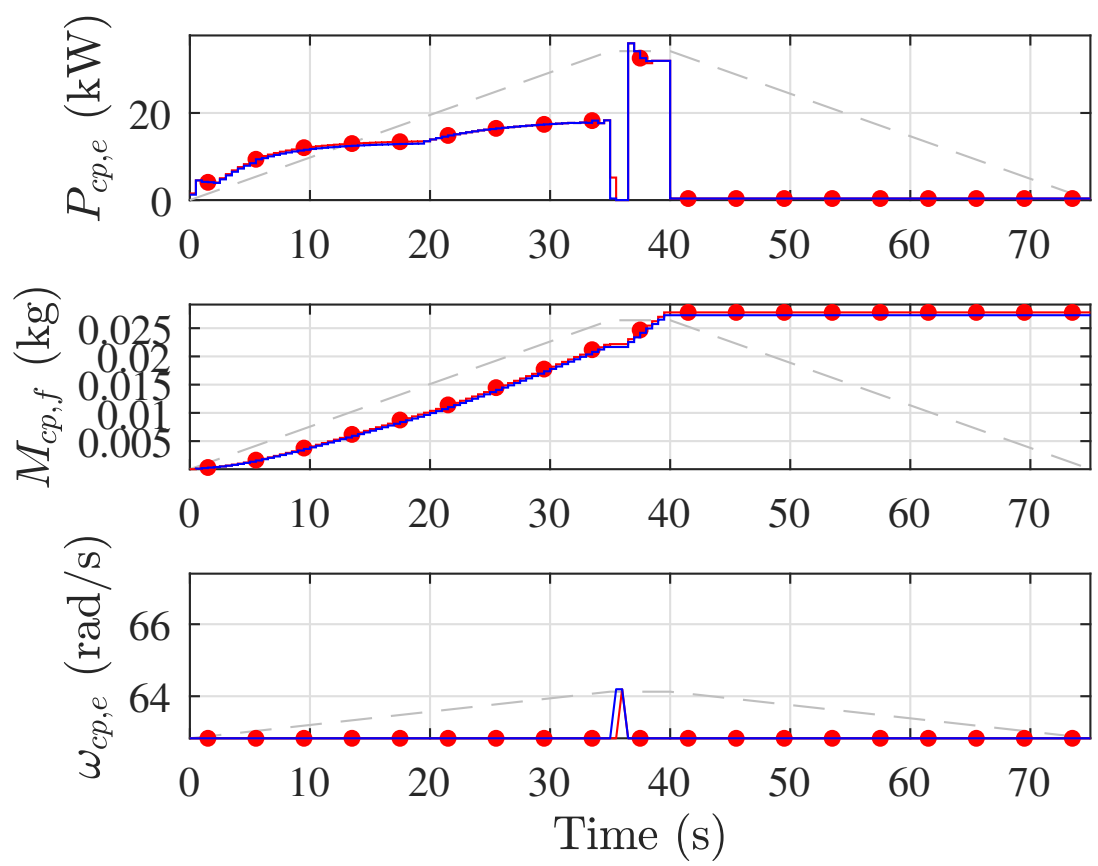

Figure 6. 15L-H truck tractor engine power (upper), fuel consumption mass (middle), and engine speed (lower) over the trapezoidal driving cycle: $(-)$ POCP value, $(\bullet)$ EOCP value, $(--)$ superimposed driving cycle.

Figures 7 and 8 show the EP mode selection and EDS electrical power and mechanical power over time. In the mode over the acceleration, the first $35 \mathrm{~s}$ is motoring/discharging, meaning the $\mathrm{CP}$ and EP are working together to propel the truck. At $35 \mathrm{~s}$, the embedded mode value is closer to generating/charging, but the projected value is motor/disgcharging, since the EP power connected to the vehicle is positive, indicating propulsive force. Over 35.5 to $36.5 \mathrm{~s}$, the generating/charging mode is active in capturing vehicle kinetic energy; similarly, the mode is active during the entire deceleration portion, corresponding with the preference for regenerative braking and charging the battery. An additional numerical experiment with an enforcement of generating/recharging over $[35,35.5]$ s showed that the initial transition from acceleration to constant velocity at $35 \mathrm{~s}$ is kept at motoring/discharging by the controller to save fuel, with a reduction of engine use; the use of the electric motor is constrained by the battery power rate limitation, resulting in the small use of frictional braking. EP mode projection was required $36 \%$ of the time $(38.7 \%$ for $11 \mathrm{~L}-\mathrm{H}$ and $30.0 \%$ for $7 \mathrm{~L}-\mathrm{H}$ ), thus bang-bang or switched solutions were obtained from the EOCP the majority of the time. The mechanical power in Figure 8 rises with the overall powertrain demand over the constant acceleration portion of the cycle and turns negative during the regenerative braking over 35.5 to $36.5 \mathrm{~s}$ and $40 \mathrm{~s}$ onward. Frictional braking, shown in Figure 5, is used at $35 \mathrm{~s}$ and during the first $7.5 \mathrm{~s}$ of the deceleration. Frictional braking is applied at 35-36 s to maintain the velocity tracking, given that the braking power rate limit and mode selection does not allow for sufficient regenerative braking otherwise. During the first $7.5 \mathrm{~s}$ of the deceleration, the frictional braking is active again because of the battery power rate limit. After $47.5 \mathrm{~s}$, the battery charging power has reached a high enough value that the braking can be entirely regenerative. Similar EP trends are observed in the $11 \mathrm{~L}-\mathrm{H}$ and $7 \mathrm{~L}-\mathrm{H}$ results. 

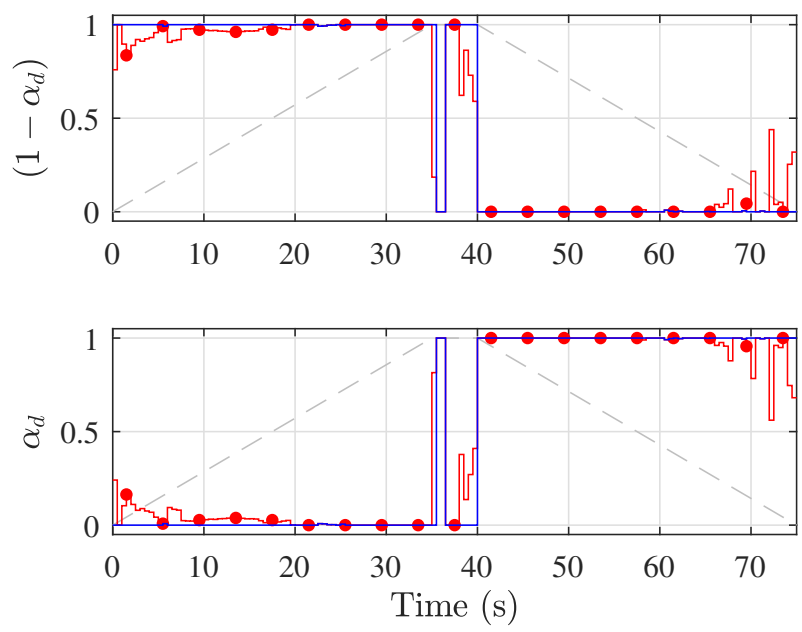

Figure 7. 15L-H truck tractor wheel electric powertrain mode selection over the trapezoidal driving cycle: $(-)$ POCP value, $(\bullet)$ EOCP value, $(--)$ superimposed drive cycle.
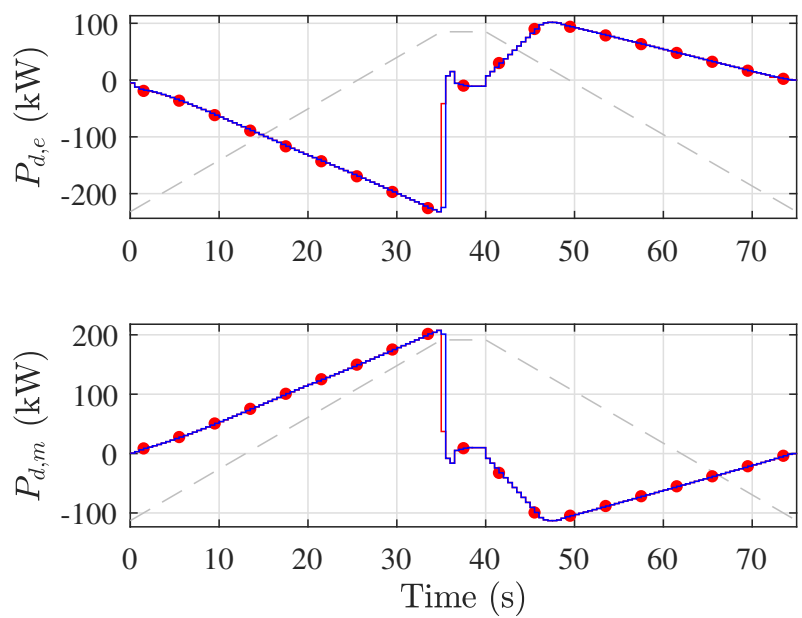

Figure 8. 15L-H truck tractor electric drive system electrical power (upper) and mechanical power (lower) over the trapezoidal driving cycle: $(-)$ POCP value, $(\bullet)$ EOCP value, $(--)$ superimposed drive cycle.

Table 1. Comparison of powertrain performances over the trapezoidal driving cycle.

\begin{tabular}{lccccc}
\hline Powertrain & $v$ MAPE & $v$ N2NE & $\bar{W}_{\boldsymbol{b}}\left(\boldsymbol{t}_{f}\right)$ & $\boldsymbol{m}_{\boldsymbol{f}}(\mathbf{k g})$ & $\Delta \boldsymbol{m}_{f}$ \\
\hline 15L-ICE & $0.78 \%$ & $0.21 \%$ & - & 0.21 & - \\
\hline $15 \mathrm{~L}-\mathrm{H}$ & $0.70 \%$ & $0.34 \%$ & 0.79 & 0.03 & $-87.29 \%$ \\
\hline $11 \mathrm{~L}-\mathrm{H}$ & $0.70 \%$ & $0.34 \%$ & 0.79 & 0.03 & $-87.69 \%$ \\
\hline $7 \mathrm{~L}-\mathrm{H}$ & $0.68 \%$ & $0.34 \%$ & 0.79 & 0.04 & $-83.07 \%$ \\
\hline
\end{tabular}

\subsection{Regulatory Drive Cycles}

Table 2 summarizes the results of the performance over the California Air Resources Board's Highway Heavy-Duty Diesel Transient driving cycle (HHDDT) and the new European driving cycle (NEDC). The driving cycles are reported without and with a charge sustaining (CS) operation. A charge sustaining operation is achieved by enforcing a lower bound $\bar{W}_{b}$ that is dependent upon the remaining drive time and current SOC:

$$
\bar{W}_{b, k+n} \geq \bar{W}_{b, k}+2 h n \frac{\left(0.8-\bar{W}_{b, k}\right)}{\left(t_{f}-t_{p, 0}\right)}, \quad n=1, \ldots, N
$$


where $t_{f}$ is the duration of the driving cycle, and the value 2 was tuned to give a suitable final charge. The charge sustaining inequality is only applied when $\bar{W}_{b}<0.8$, the power coupler is closed, the change in reference velocity is less than $0.06 \mathrm{~m} / \mathrm{s}$ between points over the prediction horizon, and the vehicle velocity is not more than $0.45 \mathrm{~m} / \mathrm{s}$ less than the reference velocity at $t_{p, 0}$. Figure 9 shows the $15 \mathrm{~L}-\mathrm{H}$ performance on the HHDDT (the NEDC profile is more well known than HHDDT and is not shown due to space considerations). Very good tracking is demonstrated by the $15 \mathrm{~L}-\mathrm{H}$, and frictional braking is only used briefly on the commanded deceleration segments when regenerative braking saturates.

Table 2. Comparison of powertrain performances over the regulatory driving cycles: California Air Resources Board's HHDDT and the European NEDC. CS: charge sustaining; $\Delta$ : percentage change.

\begin{tabular}{llccccccc}
\hline Cycle & Powertrain & $v$ MAPE & $v \mathbf{N 2 N E}$ & $\overline{\boldsymbol{W}}_{\boldsymbol{b}}\left(\boldsymbol{t}_{f}\right)$ & $\boldsymbol{m}_{f}(\mathbf{k g})$ & $\Delta \boldsymbol{m}_{f}$ & $\boldsymbol{E}(\mathbf{M J})$ & $\Delta E$ \\
\hline HHDDT & 15L-ICE & $1.03 \%$ & $3.06 \%$ & - & 20.27 & - & 873.74 & - \\
\hline HHDDT & 15L-H & $0.28 \%$ & $0.90 \%$ & 0.61 & 18.28 & $-9.82 \%$ & 838.91 & $-3.99 \%$ \\
\hline HHDDT & 11L-H & $0.49 \%$ & $1.64 \%$ & 0.54 & 17.47 & $-13.83 \%$ & 823.80 & $-5.72 \%$ \\
\hline HHDDT & 7L-H & $1.41 \%$ & $3.93 \%$ & 0.20 & 13.78 & $-32.04 \%$ & 758.29 & $-13.21 \%$ \\
\hline HHDDT (CS) & 15L-ICE & $1.03 \%$ & $3.06 \%$ & - & 20.27 & - & 873.74 & - \\
\hline HHDDT (CS) & 15L-H & $0.44 \%$ & $1.22 \%$ & 0.80 & 19.44 & $-4.09 \%$ & 838.00 & $-4.09 \%$ \\
\hline HHDDT (CS) & 11L-H & $1.14 \%$ & $3.53 \%$ & 0.80 & 18.28 & $-9.83 \%$ & 787.82 & $-9.83 \%$ \\
\hline HHDDT (CS) & 7L-H & $5.98 \%$ & $13.26 \%$ & 0.80 & 14.56 & $-28.18 \%$ & 627.55 & $-28.18 \%$ \\
\hline NEDC & 15L-ICE & $0.85 \%$ & $3.46 \%$ & - & 5.43 & - & 233.93 & - \\
\hline NEDC & 15L-H & $0.37 \%$ & $1.40 \%$ & 0.67 & 3.29 & $-39.32 \%$ & 177.43 & $-24.15 \%$ \\
\hline NEDC & 11L-H & $0.58 \%$ & $2.52 \%$ & 0.64 & 3.15 & $-42.06 \%$ & 178.29 & $-23.78 \%$ \\
\hline NEDC & 7L-H & $1.34 \%$ & $4.95 \%$ & 0.62 & 2.79 & $-48.59 \%$ & 168.64 & $-27.91 \%$ \\
\hline NEDC (CS) & 15L-ICE & $0.85 \%$ & $3.46 \%$ & - & 5.43 & - & 233.93 & - \\
\hline NEDC (CS) & 15L-H & $0.29 \%$ & $1.72 \%$ & 0.78 & 3.86 & $-28.88 \%$ & 170.67 & $-27.04 \%$ \\
\hline NEDC (CS) & 11L-H & $0.58 \%$ & $2.79 \%$ & 0.79 & 3.65 & $-32.81 \%$ & 160.27 & $-31.49 \%$ \\
\hline NEDC (CS) & 7L-H & $1.65 \%$ & $6.19 \%$ & 0.78 & 3.13 & $-42.28 \%$ & 139.80 & $-40.24 \%$ \\
\hline
\end{tabular}
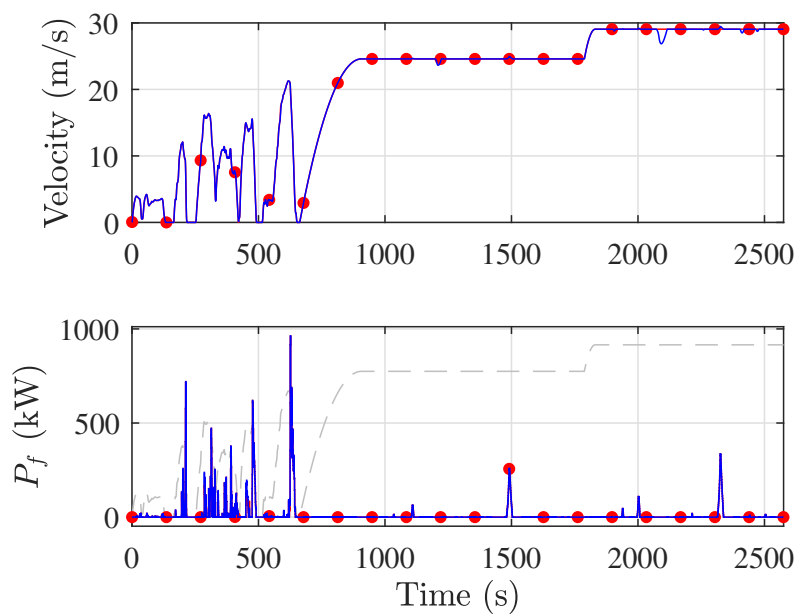

Figure 9. 15L-H truck tractor velocity and frictional braking power over the Highway Heavy-Duty Diesel Transient driving cycle: $(-)$ POCP value, $(\bullet)$ EOCP value, $(--)$ superimposed driving cycle.

Table 2 shows the hybridization results: significantly reduced fuel and a lower total energy use, where total energy includes the fuel energy plus additional energy from a 
$1 \mathrm{MW}$ fast charger to charge the battery pack back to the original 0.8 SOC. The hybrid fuel savings are greater when CS is off, which is expected since the final SOC can be less than it is with CS. Without CS, the minimum fuel savings compared to the 15L-ICE is the $15 \mathrm{~L}-\mathrm{H}$ over the HHDDT at $9.82 \%$, and the maximum is the $7 \mathrm{~L}-\mathrm{H}$ at $48.59 \%$ over the NEDC. With CS, the minimum fuel savings are $4.09 \%$ over the HHDDT, and the maximum is $40.24 \%$ over the NEDC. However, total energy savings without CS are less compared to using CS, indicating differences between the two approaches in how the battery is used and fast charger inefficiencies. Considering the velocity tracking, the 15L-H and 11L-H demonstrate that the MAPE and N2NE are similar to 15L-ICE. If the 7L-H powertrain is removed from consideration because of large MAPE and N2NE errors, then the maximum fuel savings are $32.81 \%$ for the NEDC CS and $42.06 \%$ for the NEDC without CS. In line with the $\mathrm{CO}_{2}$ modeling approach adopted by the United States Environmental Protection Agency's Greenhouse Gas Emissions Model [18], tractor $\mathrm{CO}_{2}$ emissions are taken to be directly proportional to fuel use, so the changes in $\mathrm{CO}_{2}$ are the same as the fuel changes. The simulation data presented can inform and guide the commercial adoption of hybrid truck tractors as either retrofit or new products. The greater the energy savings, the faster the recovery of additional costs incurred through hybridization.

The regulatory driving cycle results, with respect to the tested profiles, support the hypothesis that a through-the-road hybrid with a reduced engine displacement will result in reduced fuel use, total energy, and $\mathrm{CO}_{2}$ emissions compared to the original vehicle. The results indicate that the combination of reduced engine displacement from $15 \mathrm{~L}$ to $11 \mathrm{~L}$, hybridization, and CS operation results in nearly as good or better velocity reference tracking while achieving lower total energy, fuel use, and emissions compared to the 15L-ICE and 15L-H. We caution that additional evaluations of different driving cycles are needed to understand the wider applicability of this conclusion.

\subsection{Penalty Weight Study}

Table 3 shows the results of changing the velocity reference tracking and fuel use penalty weights without CS, $q_{v, \mathrm{Y}}$ and $q_{c p, W_{f}}$, respectively. We observe that increasing/decreasing $q_{v, \mathrm{Y}}$ alone results in better/worse reference velocity tracking. Similarly, increasing/decreasing $q_{c p, W_{f}}$ alone results in better/worse fuel economy and worse/better SOC. Combinations of changing $q_{v, \mathrm{Y}}$ and $q_{c p, W_{f}}$ follow similar trends. These results demonstrate that there are many reasonable options for control tuning, and the values chosen for the previously presented results are not the only ones that may produce acceptable results.

Table 3. Comparison of 15L-H performance over the trapezoidal profile with changes in the fuel use and velocity reference tracking penalty weights: $\Delta$ : percentage change.

\begin{tabular}{lccccc}
\hline Weights & $v$ MAPE & $v$ N2NE & $\overline{\boldsymbol{W}}_{\boldsymbol{b}}\left(\boldsymbol{t}_{f}\right)$ & $\boldsymbol{m}_{f}(\mathbf{k g})$ & $\boldsymbol{\Delta} \boldsymbol{m}_{f}$ \\
\hline$q_{v, \mathrm{Y}}, q_{c p, \mathrm{~W}_{f}}$ & $0.70 \%$ & $0.34 \%$ & 0.7875 & 0.03 & - \\
\hline $10 \times q_{v, \mathrm{Y}}, q_{c p, \mathrm{~W}_{f}}$ & $0.09 \%$ & $0.13 \%$ & 0.7877 & 0.03 & $15.01 \%$ \\
\hline $0.1 \times q_{v, \mathrm{Y}}, q_{c p, \mathrm{~W}_{f}}$ & $1.43 \%$ & $0.42 \%$ & 0.7876 & 0.03 & $-0.48 \%$ \\
\hline$q_{v, \mathrm{Y}}, 10 \times q_{c p, \mathrm{~W}_{f}}$ & $0.70 \%$ & $0.34 \%$ & 0.7853 & 0.01 & $-53.29 \%$ \\
\hline$q_{v, \mathrm{Y}}, 0.1 \times q_{c p, \mathrm{~W}_{f}}$ & $0.70 \%$ & $0.32 \%$ & 0.7944 & 0.08 & $205.33 \%$ \\
\hline $10 \times q_{v, \mathrm{Y}}, 10 \times q_{c p, \mathrm{~W}_{f}}$ & $0.11 \%$ & $0.13 \%$ & 0.7854 & 0.01 & $-48.17 \%$ \\
$10 \times q_{v, \mathrm{Y}}, 0.1 \times q_{c p, \mathrm{~W}_{f}}$ & $0.11 \%$ & $0.14 \%$ & 0.7917 & 0.08 & $192.64 \%$ \\
\hline $0.1 \times q_{v, \mathrm{Y}}, 10 \times q_{c p, \mathrm{~W}_{f}}$ & $1.11 \%$ & $0.41 \%$ & 0.7854 & 0.01 & $-60.36 \%$ \\
\hline $0.1 \times q_{v, \mathrm{Y}}, 0.1 \times q_{c p, \mathrm{~W}_{f}}$ & $1.63 \%$ & $0.40 \%$ & 0.7948 & 0.08 & $210.12 \%$ \\
\hline
\end{tabular}




\section{Conclusions}

The application of hybrid power to a Class $86 \times 4$ truck tractor with a high roof sleeper $\mathrm{cab}$ and a long dry van trailer was investigated under distributed switched optimal control and different engine sizings. The heavy-duty hybrid truck is a through-the-road hybrid with one axle driven by a combustion powertrain and the other axle driven by an electrical powertrain composed of an electric drive system and a battery with two modes of operation: motoring/battery discharging and generating/battery charging. Control-oriented power flow models were created for the combustion powertrain and given for the electrical powertrain. A recently developed distributed switched system control algorithm was used to manage the interactions between the combustion powertrain, the electric powertrain, and the vehicle operation. The algorithm is based upon the embedding method for solving switched optimal control problems with discrete-valued mode switches, such as the power flow direction of the electrical powertrain. A conventional $15 \mathrm{~L}$ displacement ICE-only truck and hybrid trucks with $15 \mathrm{~L}, 11 \mathrm{~L}$, and $7 \mathrm{~L}$ engine displacements were simulated over test and regulatory driving cycles. The control tuning was kept consistent between all powertrains and tests to form a consistent basis of comparison. Hybridization results showed less fuel consumption, fewer $\mathrm{CO}_{2}$ emissions, and less total energy use, even accounting for the charge sustaining operation and energy needed to return the battery's state-of-charge to the initial value, and the savings increase as the engine displacement is reduced. The drawback to the engine downsizing is that velocity reference tracking suffers over the regulatory cycles. The reasons are that the peak powers of the combustion and electrical powertrains do not align, resulting in less total deliverable power at certain engine speeds than is possible from the original $15 \mathrm{~L} \mathrm{ICE}$ alone. However, the results indicate that the combination of a reduced engine displacement from $15 \mathrm{~L}$ to $11 \mathrm{~L}$, hybridization, and CS operation results in nearly as good or better velocity reference tracking while achieving lower total energy, fuel use, and $\mathrm{CO}_{2}$ emissions compared to the 15L-ICE and 15L-H, supporting the hypothesis that improvements with hybridization and engine downsizing are achievable. We caution that additional different driving cycle evaluations are needed to understand the wider applicability of this conclusion.

Future work will include the incorporation of different electrical powertrains with peak power near that of the tested ICEs to produce a power curve similar to that of the $15 \mathrm{~L}$ ICE in an effort to reduce velocity reference tracking error while keeping significant energy savings; this will include the addition of a transmission between the axle and the current electrical powertrain. Different driving cycles will be evaluated as well to understand the broader applicability of the approach and potential benefits. Moreover, additional vehicle classes will be considered for hybridization to better understand the specific needs of commercial vehicle hybridization and how to best lower total operating costs. Further, additional optimization algorithm tunings are of interest to better understand the penalty weight effects on performance given that the control problem is nonlinear.

Author Contributions: Conceptualization, M.A. and R.T.M.; data curation, R.T.M. and M.A.; methodology, R.T.M. and M.A.; software, R.T.M. and M.A.; visualization, M.A. and R.T.M.; writing—original draft preparation, M.A. and R.T.M.; writing-review and editing, M.A. and R.T.M. All authors have read and agreed to the published version of the manuscript.

Funding: This research received no external funding.

Institutional Review Board Statement: Not applicable.

Informed Consent Statement: Not applicable.

Data Availability Statement: Simulation data upon request from contact author.

Conflicts of Interest: The authors declare no conflict of interest.

\section{Appendix A. Modeling Parameters}

The combustion engine powertrain model fit coefficients, along with the engine speed range, are given in Tables A1 and A2 for each engine. The engine speed time constant 
$\tau_{\omega_{c p, e}}=0.25 \mathrm{~s}$, which is estimated from [18]. The final drive gear efficiency for the CP and $\mathrm{EP}$ is $\eta_{f d}=0.98$.

Table A1. Diesel engine maximum power (W) model parameter coefficients.

\begin{tabular}{lcccc}
\hline Engine & $\boldsymbol{\beta}_{\boldsymbol{e}, \mathbf{3}}$ & $\boldsymbol{\beta}_{\boldsymbol{e}, \mathbf{2}}$ & $\boldsymbol{\beta}_{\boldsymbol{e}, \mathbf{1}}$ & $\boldsymbol{\beta}_{\boldsymbol{e}, \mathbf{0}}$ \\
\hline $15 \mathrm{~L}$ & $-2.18 \times 10^{-4}$ & $6.80 \times 10^{-2}$ & -3.81 & 94.7 \\
\hline $11 \mathrm{~L}$ & $-2.94 \times 10^{-4}$ & 0.102 & -8.99 & 303 \\
\hline $7 \mathrm{~L}$ & $-1.16 \times 10^{-4}$ & $4.85 \times 10^{-2}$ & -5.42 & 227 \\
\hline
\end{tabular}

Table A2. Diesel engine fuel mass flow rate $(\mathrm{g} / \mathrm{s})$ model parameter coefficients.

\begin{tabular}{lcccc}
\hline Engine & $\beta_{f, \mathbf{0}}$ & $\boldsymbol{\beta}_{f, \mathbf{1}}$ & $\boldsymbol{\beta}_{f, \mathbf{2}}$ & $\boldsymbol{\omega}_{c p, e^{\prime}}^{\min } \omega_{c p, e}^{\max }(\mathbf{r a d} / \mathbf{s})$ \\
\hline $15 \mathrm{~L}$ & -0.841 & 0.0131 & $4.94 \times 10^{-5}$ & {$[62.8,219.9]$} \\
\hline $11 \mathrm{~L}$ & -0.982 & 0.0146 & $4.86 \times 10^{-5}$ & {$[62.8,230.4]$} \\
\hline $7 \mathrm{~L}$ & -0.339 & $7.05 \times 10^{-3}$ & $4.93 \times 10^{-5}$ & {$[78.5,272.3]$} \\
\hline
\end{tabular}

The EDS maximum mechanical power is expressed in Equation (A1) as [24]

$$
P_{d, m}^{\max }\left(\omega_{d}\right)=1000 \times\left\{\begin{array}{lr}
0.428 \omega_{d}+1, & 0 \leq \omega_{d} \leq 522 \mathrm{rad} / \mathrm{s} \\
-3.46 \times 10^{-3} \omega_{d}^{3}+5.36 \omega_{d}^{2} & \\
-2.77 \times 10^{3} \omega_{d}+4.77 \times 10^{5}, & 522<\omega_{d} \leq 525 \mathrm{rad} / \mathrm{s} \\
225, & 526<\omega_{d} \leq 836 \mathrm{rad} / \mathrm{s} \\
-3.04 \times 10^{-3} \omega_{d}^{3}+7.62 \omega_{d}^{2} & \\
-6.36 \times 10^{3}+1.77 \times 10^{6}, & 836<\omega_{d} \leq 839 \mathrm{rad} / \mathrm{s} \\
-\omega_{d} /(2 \pi)+3.58 \times 10^{2}, & 839<\omega_{d} \leq 1675.5 \mathrm{rad} / \mathrm{s} .
\end{array}\right.
$$

The battery maximum capacity and discharging and fit coefficients are given in Table A3. The vehicle physical parameters are shown in Table A4. The EP driven axle ratio, $\gamma_{v, e}$, was selected to match the maximum speed of the EP with the expected maximum axle speed.

Table A3. Battery discharge and charge parameters [24].

\begin{tabular}{lcc}
\hline Parameter & Discharge, $\boldsymbol{\alpha}_{\boldsymbol{d}}=\mathbf{0}$ & Charge, $\boldsymbol{\alpha}_{\boldsymbol{d}}=\mathbf{1}$ \\
\hline$W_{b}^{\max }$ & $214.57 \times 10^{6} \mathrm{~J}$ & $214.57 \times 10^{6} \mathrm{~J}$ \\
\hline$k^{\alpha_{d}}$ & -1 & 1 \\
\hline$c_{b, 1}^{\alpha_{d}}$ & 4.76 & 55.0 \\
\hline$c_{b, 2}^{\alpha_{d}}$ & $-5.10 \times 10^{-7}$ & $1.27 \times 10^{-7}$ \\
\hline$c_{b, 3}^{\alpha_{d}}$ & 2.78 & -3.015 \\
\hline$c_{b, 4}^{\alpha_{d}}$ & $2.70 \times 10^{-12}$ & $-5.50 \times 10^{-14}$ \\
\hline
\end{tabular}


Table A4. Vehicle parameters.

\begin{tabular}{lc}
\hline Parameter & Value \\
\hline$m_{v}$ (includes payload) & $3.30 \times 10^{4} \mathrm{~kg}[18]$ \\
\hline$A C_{d}$ & $5.4 \mathrm{~m}^{2}[18]$ \\
\hline$C_{r r}$ & $6.5 \times 10^{-3}[18]$ \\
\hline$\rho_{a i r}$ & $1.23 \mathrm{~kg} / \mathrm{m}^{3}[18]$ \\
\hline$r_{w h l}$ & $0.5 \mathrm{~m} \mathrm{[18]}$ \\
\hline$v^{\max }$ & $35.8 \mathrm{~m} / \mathrm{s}$ \\
\hline$P_{f}^{\max }$ & $7.5 \mathrm{MW}$ \\
\hline$\gamma_{v, c}$ & $3.7[18]$ \\
\hline$\gamma_{v, e}$ & 23.4 \\
\hline
\end{tabular}

\section{References}

1. Çabukoglu, E.; Georges, G.; Küng, L.; Pareschi, G.; Boulouchos, K. Battery electric propulsion: An option for heavy-duty vehicles? Results from a Swiss case-study. Transp. Res. Part C Emerg. Technol. 2018, 88, 107-123. [CrossRef]

2. Quiros, D.C.; Smith, J.; Thiruvengadam, A.; Huai, T.; Hu, S. Greenhouse gas emissions from heavy-duty natural gas, hybrid, and conventional diesel on-road trucks during freight transport. Atmos. Environ. 2017, 168, 36-45. [CrossRef]

3. Miller, P. (Ed.) Reducing Heavy-Duty Long Haul Combination Truck Fuel Consumption and $\mathrm{CO}_{2}$ Emissions; Northeast States Center for a Clean Air Future (NESCCAF): Boston, MA, USA, 2009.

4. Silva Bravo, R.R.; De Negri, V.J.; Martins Oliveira, A.A. Design and analysis of a parallel hydraulic-pneumatic regenerative braking system for heavy-duty hybrid vehicles. Appl. Energy 2018, 225, 60-77. [CrossRef]

5. Barelli, L.; Bidini, G.; Ciupăgeanu, D.A.; Pianese, C.; Polverino, P.; Sorrentino, M. Stochastic power management approach for a hybrid solid oxide fuel cell/battery auxiliary power unit for heavy duty vehicle applications. Energy Convers. Manag. 2020, 221, 113197. [CrossRef]

6. Zeng, X.; Wang, Z.; Wang, Y.; Song, D. Online optimal control strategy methodology for power-split hybrid electric bus based on historical data. Int. J. Automot. Technol. 2020, 21, 1247-1256. [CrossRef]

7. Lombardi, S.; Villani, M.; Bella, G.; Tribioli, L. Retrofit of a Heavy-Duty Diesel Truck: Comparison of Parallel and Series Hybrid Architectures with Waste Heat Recovery; SAE Technical Paper 2020-24-0015; Society of Automotive Engineers: Warrendale, PA, USA, 2020.

8. Hwang, H.Y.; Lan, T.S.; Chen, J.S. Optimization and application for hydraulic electric hybrid vehicle. Energies 2020, 13, 322. [CrossRef]

9. Chen, L.; Liao, Z.; Ma, X. Nonlinear model predictive control for heavy-duty hybrid electric vehicles using random power prediction method. IEEE Access 2020, 8, 202819-202835. [CrossRef]

10. Zhang, P.; Wu, X.; Du, C.; Xu, H.; Wang, H. Adaptive equivalent consumption minimization strategy for hybrid heavy-duty truck based on driving condition recognition and parameter optimization. Energies 2020, 13, 5407. [CrossRef]

11. Gao, Z.; Finney, C.; Daw, C.; LaClair, T.J.; Smith, D. Comparative study of hybrid powertrains on fuel saving, emissions, and component energy loss in hd trucks. SAE Int. J. Commer. Veh. 2014, 7, 414-431. [CrossRef]

12. Argonne National Laboratory. Autonomie. 2021. Available online: https://www.autonomie.net (accessed on 27 September 2021).

13. Daw, C.S.; Gao, Z.; Smith, D.E.; Laclair, T.J.; Pihl, J.A.; Edwards, K.D. Simulated fuel economy and emissions performance during city and interstate driving for a heavy-duty hybrid truck. SAE Int. J. Commer. Veh. 2013, 6, 161-182. [CrossRef]

14. Ribau, J.P.; Silva, C.M.; Sousa, J.M.C. Efficiency, cost and life cycle $\mathrm{CO}_{2}$ optimization of fuel cell hybrid and plug-in hybrid urban buses. Appl. Energy 2014, 129, 320-335. [CrossRef]

15. Di Ilio, G.; Di Giorgio, P.; Tribioli, L.; Bella, G.; Jannelli, E. Preliminary design of a fuel cell/battery hybrid powertrain for a heavy-duty yard truck for port logistics. Energy Convers. Manag. 2021, 243, 114423. [CrossRef]

16. Ferrara, A.; Jakubek, S.; Hametner, C. Energy management of heavy-duty fuel cell vehicles in real-world driving scenarios: Robust design of strategies to maximize the hydrogen economy and system lifetime. Energy Convers. Manag. 2021, $232,113795$. [CrossRef]

17. Samsun, R.C.; Krupp, C.; Baltzer, S.; Gnörich, B.; Peters, R.; Stolten, D. A battery-fuel cell hybrid auxiliary power unit for trucks: Analysis of direct and indirect hybrid configurations. Energy Convers. Manag. 2016, 127, 312-323. [CrossRef]

18. Greenhouse Gas Emissions Model (GEM) User Guide, v3.8; Technical Report EPA-420-B-20-056; U.S. Environmental Protection Agency: Washington, DC, USA, 2020. 
19. Meyer, R.T. Distributed switched optimal control of an electric vehicle. Energies 2020, 3364 . [CrossRef]

20. Meyer, R.T.; Zefran, M.; DeCarlo, R.A. A comparison of the embedding method with multiparametric programming, mixedinteger programming, gradient-descent, and hybrid minimum principle-based methods. IEEE Trans. Control. Syst. Technol. 2014, 22, 1784-1800. [CrossRef]

21. Shang, Y. Scaled consensus of switched multi-agent systems. IMA J. Math. Control. Inf. 2019, 36, 639-657. [CrossRef]

22. Doktorcik, C. Modeling and Simulation of a Hybrid Ship Power System. Master's Thesis, Purdue University, West Lafayette, IN, USA, 2011.

23. Krause, P.; Wasynczuk, O.; Sudhoff, S.; Pekarek, S. Analysis of Electric Machinery and Drive Systems, 3rd ed.; John Wiley \& Sons: Hoboken, NJ, USA, 2013.

24. Meyer, R.T.; DeCarlo, R.A.; Pekarek, S. Hybrid Model Predictive Power Management of a Battery-Supercapacitor Electric Vehicle. Asian J. Control. 2016, 18, 150-165. [CrossRef] 